\title{
Effectiveness of an Educational Feedback Intervention on Drug Prescribing in Dental Practice
}

\author{
Rauniar GP, Das BP, Manandhar TR, Bhattacharya SK
}

Department of Clinical Pharmacology and Therapeutics

BP Koirala Institute of Health Sciences

Ghopa, Dharan, Nepal

Corresponding Author

G. P. Rauniar

Department of clinical Pharmacology and Therapeutics

BP Koirala Institute of Health Sciences

Ghopa, Dharan, Nepal

Email: gprauniar@hotmail.com

Citation

Rauniar GP, Das BP, Manandhar TR, Bhattacharya SK. Effectiveness of an Educational Feedback Intervention on Drug Prescribing in Dental Practice. Kathmandu Univ Med J 2012;10(4):30-35.

\section{ABSTRACT \\ Background}

Irrational use of drugs as well as inappropriate and over drug prescribing leads to unnecessary expenditures and emergence of resistant bacterial strains. Feedback intervention on drug prescribing habits and face to face educational intervention of prescription audit would be effective in rationalizing prescribing practices.

\section{Objective}

To measure the impact of educational feedback intervention on the prescribing behavior of dental surgeons.

\section{Methods}

Prospective audit of twelve hundred outpatients prescriptions in dental OPD at BPKIHS of those dental surgeon who attended the educational intervention session was collected randomly by trained persons on customized data collection sheet before and after educational intervention.

\section{Results}

A total 1200 prescription were collected, 300 before and 300 after intervention period at the internal of one month, three months and six months. Majority of the prescriptions (39.33\%) contained four drugs but after intervention, prescriptions contained mostly one drug, $73 \%$ in first month, $78.67 \%$ in third month and $65.34 \%$ in six month. Mean number of drugs per prescription after intervention were decreased. There was increased number of generic names of drugs after intervention. Amoxicillin, Metronidazole, Chlorhexidine, Povidone iodine gargle, Nimesulide, Ibuprofen, Ibuprofen + paracetamol, and Paracetamol were most commonly prescribed by dental prescribers before and after intervention. Selection of antimicrobial was done on empirical basis which was correct because Amoxicillin concentration reaches effectively in gingival crevicular fluid and Metronidazole covered effectively against anaerobic bacteria were found in orodental infection. The uses of topical anti-infective preparation as irrigants of choice that can kill majority of micro-organisms found is root canal and dental tubules and minimize systemic use of antimicrobials. Nimesulide prescribing needs to be rationalized.

\section{Conclusion}

Feedback educational intervention of prescription audit is effective to improve their prescribing behaviors and rationalize drug utilization pattern for the benefit of the patients.

\section{KEY WORDS}

Dental prescriber, drug utilization, feedback educational intervention 


\section{INTRODUCTION}

With escalating health care costs and dwindling budgets, governments around the world, especially in developing countries, are struggling to provide optimal health care. Hence, it is very important to sensitize the prescribers about dangers of polytherapy and importance of cost-effective prescribing to contain healthcare costs. The main factor leading to the growth in expenditure is the preference of prescribers for new and expensive drugs for conditions for which cheaper alternative drugs are available. ${ }^{1}$ It is recognized that changing prescriber behavior is difficult and often requires educational intervention. Intervention by feedback has been adopted in the United Kingdom to analyse the prescribing data of the practitioners. ${ }^{2}$ Prescriber feedback alone without educational intervention and audit was found to have only a modest impact. In a developing country like Nepal where prescribing habits are irrational, dental practitioners also prescribe more expensive antimicrobial agents and multivitamins to a large number of patients increasing the cost of therapy. ${ }^{3,4}$ Hence evaluation of prescriptions after educational feedback intervention on prescribing habits and comparison with the baseline data will reveal its impact on reduction in irrational use of drugs. ${ }^{5,6}$ Even a small reduction in polypharmacy would be worth while achievement in changing the prescribing behavior. ${ }^{7,8}$

Educating future healthcare providers about the importance of judicious antimicrobial use and its impact on containing health care costs would be effective in rationalizing prescribing practices. ${ }^{9}$ Pharmacotherapy is one of the most rapidly changing aspects of clinical medicine and practitioners must be knowledgeable and update their knowledge on latest trends in treatment. ${ }^{10}$ This has lead to a sharp decline in the number of antimicrobials prescribed when frequent prescription audit and feedback sessions were held with practitioners. ${ }^{11-14}$

Hence the aim of the present study was to measure the impact of educational feedback intervention on prescribing behaviour of dental surgeons at BPKIHS.

\section{METHODS}

Prospective audit of twelve hundred outpatients prescriptions in dental OPD at BPKIHS of those dental surgeon who attended the educational intervention session was collected randomly by trained persons on customized data collection sheet before and after educational intervention and feedback presented to dental prescribers and discussed. This study was approved by BPKIHS institutional ethical committee.

Principal investigator had highlighted about rational use of drugs to dental prescribers and discussed use and misuse of antimicrobial agents, multi-vitamins, benefit of generic drug and essential drug list ( EDL ) of Nepal, problem of antimicrobial resistant and disadvantages of polypharmacy.
Principle investigator had also mentioned and discussed WHO prescribing indicators method.

Principal investigator had presented baseline feedback data and discussed vigorously with dental prescribers. After baseline data intervention, 300 prescriptions were again collected by trained person at interval of one month, three months and six months to measure the impact of baseline feedback and education of rational drug use on dental prescribers.

Statistical analysis was done by using (a) WHO prescribing indicator method - mean no. of drugs/ prescription, number of prescriptions with antimicrobial agents, number of prescriptions with injections, number of prescriptions with fixed drug combinations (FDC), number of prescriptions with generic name, percentage of drugs from EDL or formulary of Nepal, and (b) ANOVA- Tukey test and P $<0.05$ was considered statistically significant. ${ }^{15}$

\section{RESULTS}

A total 1200 prescription were collected, 300 prescriptions before and 300 prescriptions after intervention period at the internal of one month, three months and six months. Six hundred eighty three (56.92\%) female and $43.08 \%$ Table 1. Trends of dental disease.

\begin{tabular}{|c|c|c|c|c|}
\hline \multirow[t]{2}{*}{ Disease } & \multicolumn{4}{|c|}{ No. (\%) } \\
\hline & $\begin{array}{l}\text { Baseline, } \\
(n=300)\end{array}$ & $\begin{array}{l}1 \text { month } \\
\text { post } \\
(n=300)\end{array}$ & $\begin{array}{l}3 \text { months } \\
\text { post } \\
(n=300)\end{array}$ & $\begin{array}{l}6 \text { months } \\
\text { post } \\
(n=300)\end{array}$ \\
\hline Dental caries & $105(35.00)$ & $\begin{array}{l}101 \\
(33.67)\end{array}$ & 52 (17.33) & 55 (18.33) \\
\hline Periodontitis & $50(16.67)$ & 34 (11.33) & $87(29.00)$ & $83(27.67)$ \\
\hline Gingivitis & $40(13.33)$ & $80(26.66)$ & 57 (19.00) & 34 (11.33) \\
\hline $\begin{array}{l}\text { Periapical } \\
\text { abscess }\end{array}$ & $25(8.33)$ & $14(4.67)$ & $13(4.33)$ & $20(6.67)$ \\
\hline Trauma & $22(7.33)$ & $5(1.66)$ & $11(3.66)$ & $10(3.33)$ \\
\hline Pulpitis & $20(5.00)$ & $33(11.00)$ & 57 (19.00) & $62(20.67)$ \\
\hline $\begin{array}{l}\text { Periodontal } \\
\text { abscess }\end{array}$ & $16(5.33)$ & $15(5.00)$ & $10(3.33)$ & $13(4.33)$ \\
\hline Cyst & $12(4.00)$ & $6(2.00)$ & $3(1.00)$ & $11(6.67)$ \\
\hline Malocclusion & $10(3.33)$ & $12(4.00)$ & $10(3.33)$ & $12(4.00)$ \\
\hline
\end{tabular}

Table 2. Educational feedback intervention effect on polypharmacy.

\begin{tabular}{|lllll|}
\hline $\begin{array}{l}\text { No. of drug } \\
\text { per pre- } \\
\text { scription }\end{array}$ & $\begin{array}{l}\text { Baseline } \\
(\mathbf{n = 3 0 0 )}\end{array}$ & $\begin{array}{l}\mathbf{1} \text { month } \\
\text { post } \\
(\mathbf{n}=\mathbf{3 0 0})\end{array}$ & $\begin{array}{l}\mathbf{3} \text { month } \\
\text { post } \\
(\mathbf{n = 3 0 0 )}\end{array}$ & $\begin{array}{l}\mathbf{6} \text { month } \\
\text { post(n=300) }\end{array}$ \\
\hline 1 drug & $68(22.66)$ & $219(73.00)$ & $236(78.67)$ & $196(65.34)$ \\
\hline 2 drug & $52(17.33)$ & $65(21.67)$ & $52(17.33)$ & $75(25.00)$ \\
\hline 3 drug & $58(19.33)$ & $12(4.00)$ & $10(3.33)$ & $18(6.00)$ \\
\hline 4 drug & $118(39.33)$ & $4(1.33)$ & $2(0.67)$ & $9(3.00)$ \\
\hline 5 drug & $4(1.33)$ & - & - & - \\
\hline 6 drug & - & - & - & $1(0.33)$ \\
\hline 7 drug & - & - & - & $1(0.33)$ \\
\hline
\end{tabular}


Table 3. Data on prescribing pattern before and after intervention.

\begin{tabular}{|c|c|c|c|c|}
\hline \multirow[t]{2}{*}{ Parameter } & \multicolumn{4}{|c|}{ No. (\%) } \\
\hline & Baseline & 1 month post & 3 months post & 6 months post \\
\hline Total no. of prescription & 300 & 300 & 300 & 300 \\
\hline Total no. of drugs & 838 & 396 & 378 & 449 \\
\hline Mean drug / prescription & 2.79 & $1.33 *$ & $1.26 *$ & $1.49 * \bullet+$ \\
\hline Total no. of prescription with AMA & $253(84.33)$ & $82(27.33) *$ & $63(21.00) *$ & $102(34.00) * \S$ \\
\hline Total no. of AMA & $344(41.05)$ & $82(20.70) *$ & $67(17.72)^{*}$ & $114(25.39) * \S$ \\
\hline Mean AMA / prescription & 1.15 & 0.27 & 0.22 & 0.38 \\
\hline $\begin{array}{l}\text { Total no. of prescription with oropharyn- } \\
\text { geal preparation }\end{array}$ & $164(54.67)$ & $93(31.00) *$ & $60(20.00) * \wedge$ & $51(17.00) * \wedge$ \\
\hline $\begin{array}{l}\text { Total no. of oropharyngeal preparation } \\
\text { prescribed }\end{array}$ & $181(21.59)$ & $95(23.98) *$ & $60(15.87)^{*} \bullet$ & $52(11.58) * \bullet$ \\
\hline $\begin{array}{l}\text { Mean no. of oropharyngeal per prescrip- } \\
\text { tion }\end{array}$ & 0.60 & 0.31 & 0.20 & 0.17 \\
\hline $\begin{array}{l}\text { Number of drugs prescribed by generic } \\
\text { name }\end{array}$ & Nil & $92(23.23) *$ & $48(12.69) * \circledast$ & $54(12.03) * \circledast \#$ \\
\hline $\begin{array}{l}\text { Number of drugs prescribed by as } \\
\text { injection }\end{array}$ & Nil & Nil & Nil & 4 \\
\hline Total no. of NSAIDs prescribed & $171(20.40)$ & 207 (69.00) ף & $236(78.67)$ ๆ \{\} & $256(85.33)$ ๆ \{\} \\
\hline Total no. of prescription with NSAIDs & $171(57.00)$ & 207 (52.27) ๆ & $236(62.43)$ ๆ \{\} & $259(57.68)$ ๆ \{\} \\
\hline Mean no. of NSAIDs / prescription & 0.57 & 0.69 & 0.78 & $0.86)$ \\
\hline Total no. of multivitamins & $142(47.33)$ & $3(1.00) *$ & $5(1.67) *$ & $9(3.00) *$ \\
\hline $\begin{array}{l}\text { Total no. of prescription with multivi- } \\
\text { tamins }\end{array}$ & $142(16.94)$ & $3(0.75) *$ & $5.1 .32) *$ & $9(2.00) *$ \\
\hline Mean no. of vit/ prescription & 0.47 & 0.01 & 0.01 & 0.03 \\
\hline $\begin{array}{l}\% \text { of drug from Essential drug list of } \\
\text { Nepal }\end{array}$ & $458(54.65)$ & $148(37.37) *$ & $123(32.54)^{*}$ & $201(44.77) *$ \\
\hline Fixed dose drug combination & $46(5.49)$ & $15(3.79)$ & $81(21.43)$ & 69 (15.37) \\
\hline
\end{tabular}

Note: P-value less than 0.05 considered significant.

* Decrease mean no. of drug per prescription, highly significant compared to baseline

- It was not significant when compared to first month.

$\S$ It was also significantly increased AMAs prescription and AMA when compared to 3rd month post.

^ Significantly decreased compared to 1 month post

® Significantly decreased compared to 1 month post.

+ Significantly increased mean number of drug compared to 3rd month post.

\# There was no significant change compared to 3rd month post.

I Significantly increased prescription with NSAIDs and number of NSAIDs compared to base line

\{\}Significantly increased number of prescription with NSAIDs and number of NSAIDs compared to 1 month.

(517) male patients were attended during study period; age ranging from three to 80 years. The most common dental disease found was dental caries, periodontitis, gingivitis, pulpitis, dental abscess etc (Table 1). Majority of the prescriptions (39.33\%) contained four drugs in base line but after intervention, prescriptions contained mostly one drug, $73.00 \%$ in first month, $78.67 \%$ in third month and $65.34 \%$ in six month (Table 2). Before intervention, only $39.99 \%$ of prescriptions contained between one to two drugs but after intervention, $90 \%$ or above prescriptions contained the same number of drugs. There was significantly decreased mean number of drugs per prescription after intervention in first, third and six months, compared to base line and this effect persisted till six months of our study when it was compared with third month's data (Table 3).

There was a significant decrease in antimicrobial containing prescriptions as well as number of antimicrobial agents (AMA) after intervention in first, third and six months when it was compared to baseline data; but antibiotic number and antibiotic containing prescriptions significantly increased after six months when compared to first and third months. However, there was no significant change in third month as compared to first month post intervention. 
Table 4. Most commonly prescribed drugs before and after intervention.

\begin{tabular}{|c|c|c|c|c|}
\hline \multirow{2}{*}{$\begin{array}{l}\text { Name of } \\
\text { drugs }\end{array}$} & \multicolumn{4}{|c|}{ No. of prescription (\%) } \\
\hline & $\begin{array}{l}\text { Baseline } \\
(n=838)\end{array}$ & $\begin{array}{l}1 \text { month } \\
\text { post } \\
(n=396)\end{array}$ & $\begin{array}{l}3 \text { month } \\
\text { post } \\
(n=378)\end{array}$ & $\begin{array}{l}6 \text { months } \\
\text { post } \\
(n=449)\end{array}$ \\
\hline Multivitamins & $142(16.94)$ & $8(2.02)$ & $5(1.32)$ & $11(2.45)$ \\
\hline Amoxicillin & $120(14.31)$ & $63(15.90)$ & $52(13.75)$ & 65 (14.47) \\
\hline Nimesulide & 103 (12.29) & $170(42.92)$ & $126(33.33)$ & $136(30.29)$ \\
\hline $\begin{array}{l}\text { Chlorhexi- } \\
\text { dine mouth } \\
\text { wash }\end{array}$ & $95(11.33)$ & $44(11.11)$ & $24(6.34)$ & 35 (7.79) \\
\hline $\begin{array}{l}\text { Metronida- } \\
\text { zole }\end{array}$ & $90(10.73)$ & $13(3.28)$ & $9(2.38)$ & 17 (3.79) \\
\hline Doxycycline & $56(6.68)$ & $1(0.25)$ & $6(1.58)$ & $4(0.89)$ \\
\hline $\begin{array}{l}\text { Povidone } \\
\text { iodine gargle }\end{array}$ & $50(5.96)$ & $9(2.27)$ & - & $3(0.67)$ \\
\hline Ibuprofen & $47(5.60)$ & $4(1.01)$ & 19 (5.02) & $24(5.34)$ \\
\hline $\begin{array}{l}\text { Amoxicillin + } \\
\text { cloxacillin }\end{array}$ & $25(2.98)$ & $3(0.75)$ & - & $4(0.89)$ \\
\hline $\begin{array}{l}\text { Ibuprofen + } \\
\text { paracetamol }\end{array}$ & $21(2.50)$ & $12(3.03)$ & $81(21.42)$ & 50 (11.10) \\
\hline $\begin{array}{l}\text { Listerine } \\
\text { mouth wash }\end{array}$ & - & 36 (9.09) & $33(8.73)$ & $6(1.38)$ \\
\hline Paracetamol & - & $13(3.28)$ & $9(2.38)$ & $32(7.13)$ \\
\hline Diclofenac & - & - & - & $16(3.56)$ \\
\hline $\begin{array}{l}\text { Thermoseal } \\
\text { tooth paste }\end{array}$ & - & - & - & $8(1.78)$ \\
\hline $\begin{array}{l}\text { Ampicillin + } \\
\text { Cloxacillin }\end{array}$ & - & - & - & 15 (3.34) \\
\hline
\end{tabular}

There was a significantly decreased oropharyngeal preparation containing prescriptions as well as number of oropharyngeal preparations used after intervention when compared to baseline data. There was also significantly decreased total number of multivitamin containing prescriptions and number of multivitamins in first month, third and sixth months post intervention. In our study it was observed that there was increased number of NSAIDs containing prescriptions as well as total number of NSAIDs used. These increases were highly significant compared to base line after intervention. These increasing effects were significantly persisting in third and sixth months post intervention, as compared with first month, but there was no significant change seen in sixth month post intervention compared to third month. There was significantly increased number of drugs prescribed by generic names after intervention in first, third and sixth month, compared to baseline but increasing effect was significantly declined in third and sixth month when it was compared to first month (Table 3).

Number of drugs prescribed in injection form was nil because almost all the drugs were prescribed in either oral form or topical form. It was also observed that number of drugs prescribed from the Essential drug list of Nepal was significantly decreased in first, third and sixth months.
Before intervention, five most commonly prescribed drugs were multivitamins (16.94\%) followed by Amoxicillin (14.31\%), Nimesulide (12.29\%), Chlorhexidine (11.33\%) and Metronidazole (10.73\%) but after intervention most common drug was Nimesulide (42.92\%) followed by Amoxicillin (15.90\%), Chlorhexidine (11.11\%), listerine mouth wash $(9.09 \%)$ Metronidazole $(3.28 \%)$ in the first month while five most commonly drugs were seen in $3^{\text {rd }}$ month like Nimesulide prescribed (33.33\%) followed by Ibuprofen + paracetamol (21.42\%), Amoxicillin (13.75\%), listerine $(8.73 \%)$ and Chlorhexidine $(6.34 \%)$ but in the sixth month, five most commonly prescribed drugs were Nimesulide (30.29\%) followed by Amoxicillin (14.47\%), Ibuprofen + paracetamol (11.10\%), Chlorhexidine (7.79\%) and Ibuprofen (5.34\%) (Table 4). Among antimicrobial agents, Amoxicillin and Metronidazole were most commonly prescribed before and after intervention. As topical oropharyngeal preparation, Chlorhexidine was most commonly prescribed followed by povidone iodine gargle both before and after intervention; but there was an increasing trend of Listerine prescriptions after intervention also. Nimesulide was most commonly prescribed by dental prescribers before and after intervention followed by Ibuprofen, Ibuprofen + paracetamol, Paracetamol. Selection of Nimesulide after intervention by dental surgeon was the commonest choice.

\section{DISCUSSION}

Rational use of drugs is a crucial problem in the current context of health care systems confronting continued pressure to provide high quality care. Modifying prescribing patterns has proved to be a formidable challenge to those seeking to promote rational drug use. Inappropriate prescribing include the use of products of doubtful effectiveness and over prescribing of effective drugs such as antibiotics lead to suboptimal care, unnecessary expenditures and the promotion of resistant bacterial strains. Prescribers are primarily concerned with the effectiveness and safety of drug.

Antibiotics prophylaxis without bacteriological investigation may increase antimicrobial resistance. But in dental practice getting uncontaminated material for culture and sensitivity may not always be possible as also the prohibitive cost of culture and sensitivity. But selection of AMA was done on empirical basis which was correct because Amoxicillin concentration reaches effectively in gingival crevicular fluid and doxycycline promotes healing in periodontal disease by stabilizing collagens. ${ }^{16,17}$ Metronidazole covered effectively against anaerobic bacteria because in Saini et al study $100 \%$ aerobes and $80 \%$ anaerobes were found in normal gingival sample while 96 to $97 \%$ isolated aerobes and anaerobes were found in orodental infection which were found more sensitive to penicillin and metronidazole. ${ }^{18}$ Selection of these AMA definitely decreases the risk of infective endocarditis 
infection by following procedures by adopting antibiotic guideline developed by American Heart Association. ${ }^{19}$ Prevention of such infection has less benefitted the patients' then doctors because prescriber do not want any risk. The incidence of Endocarditis infection incidence is very low due to dental procedure or dental disease than medical diseases but increases economical burden to the patient. ${ }^{20-22}$ In our study though earlier antibiotic utilization was very high, the selection was appropriate but after the intervention, antibiotic prescribing habit was decreased in the later part of study which was not significant. There were increased use of topical anti-infective preparation like chlorhexidine, Listerine in our study as irrigants of choice that can kill majority of micro-organisms found is root canal and dental tubules and minimize systemic use of AMAs.

Presenting prescribers with research and evidence based data can be effective intervention in changing prescribing habit. ${ }^{23}$ Face to face education visits by trained personnel with individual health practitioners have consistently shown to be effective in changing behaviors and prescribing practice. ${ }^{24}$ Feedback is successful when it is immediate, specific and able to identify the problem. By combining the methods of educational outreach with audit and feedback to deliver concurrent prescriber feedback to change prescribing behavior. ${ }^{25}$

Prescribers need to be aware of the issues and believe the quality use of medicines is important. They need to be able to recognize when they have to act. Each country used different feedback methods and all were successful because sharp decline in number of drug use and antibiotic but the effect decayed once feedback stopped which was also seen in our study. ${ }^{11,13,26,27}$ The potential of practice communities as a variety of formal and informal, internal and external professional groups, team gathering associations, societies in which identification of the individual professional to influence the value of doctors and dentists. ${ }^{28}$ Practitioners need to promote their carrier goals for enhancement of quality of care. Educating of health care providers, whether medical or dental, about the importance of judicious use of antibiotics, and other categories of drugs, is very important to prevent antibiotic resistance as well as minimize the poly- pharmacy by feedback and face to face education strategies to enhance effectiveness. Our study showed prevalence and incidence of dental disease were similar before and after intervention but mean number of drug utilization was high in baseline which was decreased after intervention and subsequently decreases polypharmacy.

NSAIDs are valuable for managing the dental pain and inflammation. Dentists relied exclusively on either Paracetamol or on agents like Ibuprofen, Diclofenac ( have risk of gastrointestinal irritation, ulceration, bleeding) or selective cyclo-oxygenase- 2 inhibitor such as Nimesulide, celecoxib etc to minimize adverse systemic effect. NSAIDs also stabilizes the periodontal condition by reducing the rate of alveolar bone resorption. ${ }^{29}$ In our study most commonly prescribed NSAID was Nimesulide in more than
$50 \%$ of cases followed by Ibuprofen and paracetamol either alone or in combination, before and after intervention. Selection of Nimesulide in our study was the primary choice because of less adverse effects and good tolerability except rare hepatotoxicity (mechanism is not unknown, probably caused by idiosyncratic reaction). ${ }^{30}$ Dental prescriber has never seen any such toxicity in their patients at BPKIHS and were reluctant to this reaction and preferred Nimesulide,though recently several instances of fulminant hepatic failure have been reported with this drug and it has not been marketed in many countries having effective ADR monitoring like UK,USA,Australia,Canada. ${ }^{31}$

In our study, before intervention multivitamins were prescribed $16.94 \%$ of the total drug prescribed as rejuvenating agents which may increase economic burden to the patient but after intervention dental prescribers reduced use of multivitamins which was highly significant and this significant reduction effect seen in the entire intervention study period. ${ }^{32}$ Vitamines, analgesics and antimicrobials were the most commonly prescribed fixed dose drug combination (FDC) in present study (table 4) and such FDC use was also seen in medical patient reported by Rauniar et al. ${ }^{33}$ There was decreased number of FDC use after intervention by dental prescribers, only preferred combination was Ibuprofen plus paracetamol because their different spectrum as an analgesic and anti-inflammatory agent provides greater benefit and minimal adverse effect. ${ }^{34}$ This proves the rationality of such use.

There was no drug prescribed in injection form except local anesthetic which was not included in this study. The dental prescribers are not willing to prescribe by generic names because dental prescribers did not wanted to substitute the branded drugs because same drugs from other brands may not be of as good quality in our region. Generically prescribed drugs may be dispensed as a branded product or lower cost non-branded one, quality wise which may not be as good. ${ }^{35}$ Prescribers preferred drugs from branded companies which is safe for their patient. Only about 30$50 \%$ of the drugs were prescribed from essential drug list of Nepal before and after intervention. Prescribers wanted to update essential drug list of Nepal and include few new common safe and effective drugs.

\section{CONCLUSION}

Prompt detailed prescriber feed back and face to face educational intervention of prescription audit is effective because there is decrease in the use of unnecessary drugs, antimicrobials, multivitamins, and an increase in the use of generic name of drugs.

If such feedback and educational intervention of prescription audit could be carried out on other specialties like medical and surgical health care, then definitely it would improve their prescribing behaviors and rationalize drug utilization pattern. 


\section{ACKNOWLEDGEMENT}

The authors are grateful to BPKIHS research committee for granting fund to carry out this study at dental OPD at BPKIHS, Nepal. The authors also thank to Mr. Gokaran Bhandari,
Mr. Jay Narayan, Mr. Harka Limbu, Mr. Uttam Shrestha et.al for data collection, Mr. Suraj Niraula, Assistant Professor, Statistics, for the statistical analysis, Mr. Randhir Kumar for data entry. The authors are also thankful to Miss Radha Regmi, Mrs. Rusha Tamrakar and Mr. Manjul Bhandari for their technical and secretarial support.

\section{REFERENCES}

1. O' Connel DL, Henry D Tomlins R .Randomized Controlled trial of effect of feedback on general practioners's prescribing in Australia. BMJ 1999; 318 (20): 507-511.

2. Majeed A, Evans N, Heal P. What can PACT tell us about prescribing in general practice. BMJ 1997; 315:1515-9.

3. Kafle KK, Khanal DM. Drug prescribing in out patient care in Nepal. J. Inst. Med 1994; 16:192-195.

4. Rauniar GP, Sahanaj MS, Das BP and Naga Rani MA. A prospective study of drug utilization and dental disease pattern at this dental department of tertiary care teaching hospital in Eastern Nepal. JNMA 2001; 40:6-11.

5. Wensing $M$, Grol R. Single and combined strategies for implementing changes in primary care: a literature review. Int. J Qual Health Care 1994; 6:115-32.

6. Oxman AD, Thomson MA, Dvis DA, Haynes RS. No magic bullets: a systemic review of 102 trials of intervention to improve professional practice. Can Med Assoc J 1995; 153:1423-31

7. Schoenbanum Sc. Feedback of clinical practice information. HMO pract 1993; 7:5-11.

8. Thomson MA, Oxman AD, Davis DA. Audit and feedback to improve health professional practice and health care outcomes. In Cochrane collaboration. Cochrane library. Issue 3 oxford: update software, 1998.

9. Belongia EA, Scheartz B. Strategies for promoting judicious use of antibiotic by doctors and patients. BMJ 1998; 317:668-71.

10. Kane RL, Garrard J. Changing physician prescribing practices. JAMA 1994; 271(5):393-94

11. Hock WVD. Prescribing audit for antibiotics in a district hospital. Trop doc 1994; 4:85-86.

12. Hidayati S, Munawarho S, Surywati S. Reducing antibiotic overuse in children with upper respiratory tract infection utilizing a small group educational intervention followed by self assesment. $\mathrm{Br} J \mathrm{Clin}$ Ppharmacol 2000; 315

13. Bishop N, Maling T. Effectiveness of a multi model intervention to modify antibiotic choice. Br J Clin Pharmacol 2000; 97.

14. Isah $A$, Isah $E$, Okojire $O$. The use of reference values for prescribing indicators as intervention tools for promoting the rational use of drugs. Br J Clin Pharmacol 2000; 89

15. How to investigate drug use in health facilities. WHO/DAP/93-1:10

16. Tenenbaum H, Jehl F, Gallion C, Dahan M. Amoxicillin and Clavulanic acid concentrations in gingival crevicular fluid. J Clin periodontal 1997; 24(11):804-7.

17. Cianco SG. Current dental chemotherapeutics. Part 2. Dent Today 1999; 16(3):48-50.

18. Saini S, Aparna, Khanna P, Mahajan A. Antibiotic susceptibility of bacterial isolates in gingivitis and periodontitis. JIDA 2003; 74:216221.

19. Epstein JB. Infective endocarditis: Dental implications and new guidelines for antibiotic prophylaxis. American Heart Association. J Can Dent Assoc 1998; 64(4):281-286

20. Drangsholt MT. A new causal model of dental disease associated with endocarditis. Ann periodontol 1998; 3(1):184-96.

21. Franklin CD. The etiology, epidemiology pathogenesis and changing pattern of infective endocarditis with a note on prophylaxis. Br Dent J 1992; 172(10): 369-373.

22. Pallasch TJ, Slots J. Antibiotic prophylaxis and the medically compromised patient. Periodontal 2000. 1996; 10:107-138.

23. Le grand A, Hogerzeil HV, Haaizer- Ruskamp FM. Intervention research in rational use of drug: a review. Health Policy Plan 1999; 14:89-102.

24. Thomson MA, Oxman AD, Davis DA, Haynes RB, Freemaritle N, Harvey EL. Educational out reach visits: effects on professional practice and health care outcome (Cochrane Review). In: The Cochrane Library. Oxford update software; 1:2001.

25. Seto WH, Ching TY, Kou M, Chiang SC, Lauder IJ, Kumana CR. Hospital antibiotic prescribing successfully modified by immediate concurrent feedback. BJ Clin Pharmacol 1996; 41:229-34.

26. Parkes A. Prescriber feedback in Australia. Australian prescriber 1998; 21:2-3.

27. Bateman DN. Prescriber feedback in England. Australian prescriber 1998; 21:3-4.

28. Parboosingh J. Continuing education and professional development for hospital doctors and dentists. Med Edu 2000; 34:421-423.

29. Salvi GE, Lang NP. The effects of non-steroidal anti-inflammatory drugs (selective and non-selective) on the treatment of periodontal disease. Curr pharm des 2005; 11(14): 1757-69.

30. Ferreiro C, Vivas S, Jorquera F, et al. Toxic hepatitis caused by Nimesulide: Presentation of new case and review of the literature. Gastroenterol hepatol 2000; 23(9):428-30.

31. Tripathi KD. Non-steroidal anti-inflammatory drugs and antipyretic analgesics. In:Essentials of medical pharmacology.5th ed. New Delhi, Jaypee Brothers Medical Publishers (P) Ltd,2004;167-184.

32. Laurence DR, Bennett PN, Brown MJ. Topics in drug therapy. In: Clinical Pharmacology. 8th ed. Singapore, Longman Singapore publishers (Pte) Ltd 1997; 3-36.

33. Rauniar GP, Naga Rani MA. Utilization of fixed dose drug combination J Nepalgunj Med Coll 2003; 2(3):38-41.

34. Laurence DR. Bennett PN, Brown MJ. Pain analgesic. In: Clinical Pharmacology. 8th ed. Singapore, Longman Singapore publishers (Pte) Ltd, 1997; 285-309.

35. Walley T, Burrill P. Generic prescribing: time to regulate the market? BMJ 2000; 320:131-2 